\title{
Assessing the degradation of ochratoxin a using a bioassay: the case of contaminated winery wastewater
}

\author{
R. Nogueira*, I. Estevinho*, L. Abrunhosa*, C. Mendonça*, P. Machado*, M. Carballa**, \\ A.G. Brito* and A. Venâncio*
}

*Institute for Biotechnology and Bioengineering, Centre for Biological Engineering, Universidade do Minho, Campus de Gualtar 4710-057, Braga, Portugal (E-mail: regina@deb.uminho.pt; agbrito@deb.uminho.pt; avenan@deb.uminho.pt)

**School of Biochemical Engineering. Pontificia Universidad Católica de Valparaíso. General Cruz 34, Valparaiso, Chile (E-mail: marta.carballa@ucv.cl)

\begin{abstract}
In vineyards the presence of certain fungi may lead to the production of the mycotoxin ochratoxin A (OTA) and subsequent contamination of grapes and wine. Furthermore, winery wastewaters contaminated with OTA may represent an environmental hazard. Therefore, it is imperative to assess the fate of this mycotoxin in conventional wastewater treatment systems. The aim of the present work was to assess the biological degradation of OTA. Experimental work was carried out in batch experiments with initial OTA to biomass concentration ratios of $1.4 \mu \mathrm{g} \mathrm{mg}^{-1}, 7.4 \mu \mathrm{g} \mathrm{mg}^{-1}$ and, $11.9 \mu \mathrm{g} \mathrm{mg}^{-1}$. The assays were inoculated with activated sludge biomass unadapted to the substance under examination. The proposed bioassay demonstrates that OTA concentrations up to $100 \mu \mathrm{gL}^{-1}$ can be degraded by microbial activity in activated sludge.
\end{abstract}

Keywords Activated sludge; bioassay; biodegradability; ochratoxin A; OECD; winery wastewater

\section{Introduction}

Ochratoxin A (OTA) is a mycotoxin that is a secondary metabolite produced by certain filamentous fungi (Figure 1). Only two fungal genera have species able to produce OTA: Aspergillus and Penicillium. It is considered one of the main mycotoxins hazardous for human health, with nephrotoxic, nephrocarcinogenic, teratogenic, and immunosuppressive properties (CAST, 2003). The presence of OTA producing fungi in vineyards may lead to contamination of grapes before the harvest and consequently to contamination of the wine produced and the wastewater generated in the production process (Fernandes et al., 2007). Wineries generate large volumes of wastewater mainly from various washing operations during the crushing and pressing of grapes as well as from rinsing of fermentation tanks, barrels and other equipment (Brito et al., 2007).

Little is known about mycotoxin biodegradation, in particular the fate of these metabolites in wastewater treatment systems and the toxic effects of contaminated wastewater discharges into natural waters. The strategy for testing the biodegradability of chemicals adopted by the Organization for Economic Co-operation and Development (OECD) consists of three levels (Painter, 1995): ready biodegradability tests or screening tests, inherent biodegradability tests and simulation tests. Depending on the test results, three levels of degradability are distinguished: readily biodegradable, inherently biodegradable and persistent. The tests are batch or (semi-)continuous and they differ in the amount of biomass and substrate concentration used.

The test for the 'readily biodegradable' level is relatively stringent as the incubation time is limited. Furthermore, the inoculum is of low density and unadapted to the chemical being tested, since it is taken directly from environmental sources such as activated 




Figure 1 Chemical formula of OTA

sludge, sewage effluents, surface waters and soils, or from a mixture of these (Blok and Balk, 1994; OECD, 1992). The test itself consists of adding the test chemical as the only carbon source to an inoculated mineral medium. After initial biodegradation is established, a so-called lag phase is allowed to pass, in which $10 \%$ of the chemical is consumed. The chemical can be classified as 'readily biodegradable' if after the end of the lag phase the subsequent extent of degradation exceeds a defined 'pass' level within a 10-day window. The required value for the pass level depends on the method used for analyzing the amount of residual chemical: $80 \%$ for specific analysis, $70 \%$ for dissolved organic carbon (DOC) and $60 \%$ for theoretical oxygen demand (ThOD) or theoretical $\mathrm{CO}_{2}$ production $\left(\mathrm{ThCO}_{2}\right)$ analyses (Painter, 1995). If a chemical does not pass the 'ready'-level test, either degradation starts too late or it occurs too slowly. The different OECD tests for 'readily biodegradable' are: DOC die-away, $\mathrm{CO}_{2}$ evolution, manometric respirometry, modified OECD screening, closed bottle and MITI(I) (OECD, 1992). To test for 'inherent' biodegradability, a higher concentration of inoculum and a longer incubation time are used than in the 'ready' tests. The Zahn-Wellens test lasts for 28 days (Painter, 1995) while the semi-continuous activated sludge test (SCAS) has a maximal duration of 12 to 26 weeks (OECD, 1984). To assess the biodegradability potential that is relevant in the environment, deviations from environmental conditions should be avoided in the lab tests. When a chemical has not passed a 'ready'-level test, but passes a test for inherent biodegradability, an additional simulation test may be started. The OECD simulation test is based on the OECD confirmatory test for surfactant biodegradation and uses the Husmann apparatus (OECD, 2001). This test basically simulates a wastewater treatment plant process with representative hydraulic and sludge retention times.

The purpose of this study was to evaluate a bioassay according to OECD standards in order to classify the degradation potential of ochratoxin A from winery wastewater.

\section{Materials and methods}

\section{OTA degradation bioassay}

To assess the biological degradation of OTA, several batch assays were conducted. In one line of experiments synthetic substrate solutions were utilized, which were contaminated with OTA concentrations ranging from 5 to $100 \mu \mathrm{g} \mathrm{L}^{-1}$. Acetate was added to represent soluble organic matter. The synthetic solution was composed as follows: $643 \mathrm{mg} \mathrm{L}^{-1}$ $\mathrm{NaCH}_{3} \mathrm{COO} \cdot 3 \mathrm{H}_{2} \mathrm{O}, 130 \mathrm{mg} \mathrm{L}^{-1} \mathrm{NH}_{4} \mathrm{Cl}, 210 \mathrm{mg} \mathrm{L}^{-1} \mathrm{NaHCO}_{3}, 44 \mathrm{mg} \mathrm{L}^{-1} \mathrm{KH}_{2} \mathrm{PO}_{4}$ and trace element solution $1 \mathrm{mLL}^{-1}$. The $\mathrm{pH}$ was adjusted to 7.5 (Vishniac and Santer, 1975). A second line of experiments was conducted with real winery wastewater contaminated with defined amounts of OTA.

Experiments were performed in Erlenmeyer flasks with an effective volume of $10 \mathrm{~mL}$, placed in an orbital shaker at $20^{\circ} \mathrm{C}$. Two control assays were included in the procedure: 
uncontaminated assays (without OTA) and assays with OTA as a single carbon source. The assays were always conducted in duplicate. Activated sludge from a winery wastewater treatment plant was used as inoculum, the average initial biomass concentration being $10 \mathrm{mg} \mathrm{L}^{-1}$ determined as volatile suspended solids (VSS). The degradation progress of OTA and acetate was assessed in samples filtered with a $0.22 \mu \mathrm{m}$ filter. To evaluate the effect of biosorption on OTA removal, batch experiments were also conducted with sludge previously inactivated by autoclaving at $121^{\circ} \mathrm{C}$. Abiotic losses like adsorption to glass were also checked.

OTA was purchased from Sigma, in crystalline form. A stock solution of $1 \mathrm{mg} \mathrm{L}^{-1}$ was prepared in toluene-acetic acid $(99: 1)$ and stored at $-20^{\circ} \mathrm{C}$. The OTA concentration of this solution was determined accurately by UV spectrophotometry at $331 \mathrm{~nm}$. OTA working solutions were prepared in $50 \mathrm{gL}^{-1} \mathrm{NaHCO}_{3}$ and used to spike the assays previously described.

\section{Analytical methods}

Ochratoxin A determination was conducted by high-performance liquid chromatography (HPLC) on samples pre-filtered with glass fiber filters. Ochratoxin A quantification was done according to Abrunhosa et al. (2002). The samples were injected directly into a HPLC equipped with a Jasco FP-920 fluorescence detector $(330 \mathrm{~nm}$ excitation wavelength; $460 \mathrm{~nm}$ emission wavelength). Chromatographic separations were performed on a C18 column (Waters Spherisorb ODS2, $4.6 \mathrm{~mm} \times 250 \mathrm{~mm}, 5 \mu \mathrm{m}$ ). The mobile phase used was pumped at $1.0 \mathrm{~mL} \mathrm{~min}^{-1}$ and consisted of an isocratic program as follows: acetonitrile/water/acetic acid (99:99:2, v/v). The injection volume was $100 \mu \mathrm{L}$.

Acetate was analyzed using a HPLC system (Knauer) with a $210 \mathrm{~nm}-\mathrm{UV}$-detection and an organic acid column (PL Hi-Plex H, $300 \mathrm{~mm} \times 7.7 \mathrm{~mm}$, Polymer Laboratories) at $65^{\circ} \mathrm{C}$. The mobile phase consisted of an aqueous $\mathrm{H}_{2} \mathrm{SO}_{4}$ solution $\left(2 \mathrm{mmol} \mathrm{L}^{-1}\right)$ at a flow rate of $0.7 \mathrm{~mL} \mathrm{~min}^{-1}$.

Activated sludge volatile suspended solids were determined according to Standard Methods (1989).

\section{Results and discussion}

Figure 2 represents actual biodegradation assays both with the synthetic substrate solution and a real winery effluent performed at distinct ratios of the initial OTA concentration to the initial biomass concentration $\left(S_{0} / X_{0}\right)$. The diagram illustrates that the OTA degradation rates (corresponding to the curves' slopes) increased with the initial contaminant concentration, both for synthetic and real wastewater. In Figure 2a, the curves' sigmoidal shapes indicate that, in accordance with the findings of Chudoba et al. (1992), the OTA degradation was accompanied by cellular multiplication.

Figure 3 depicts the specific degradation rate of OTA as a function of the $S_{0} / X_{0}$ ratio. The specific degradation rate was calculated as the ratio between maximum removal speed and the initial biomass concentration. According to the represented results the specific degradation rate is directly proportional to the $S_{0} / X_{0}$ ratio.

In order to assess biosorption and adsorption effects on the experimental results, blank assays were conducted with identical equipment as the previous experiments, but with an inoculum inactivated by autoclaving. As illustrated by Figure 4, no diminution of the initial OTA concentration occurred during 90 hours, so that both biosorption and adsorption effects could be excluded.

As illustrated by Figure 5, the experiments described above also demonstrated that OTA concentrations up to $100 \mu \mathrm{g} \mathrm{L}^{-1}$ had no significant effect on the biological removal of soluble organic matter (here represented by acetate). 

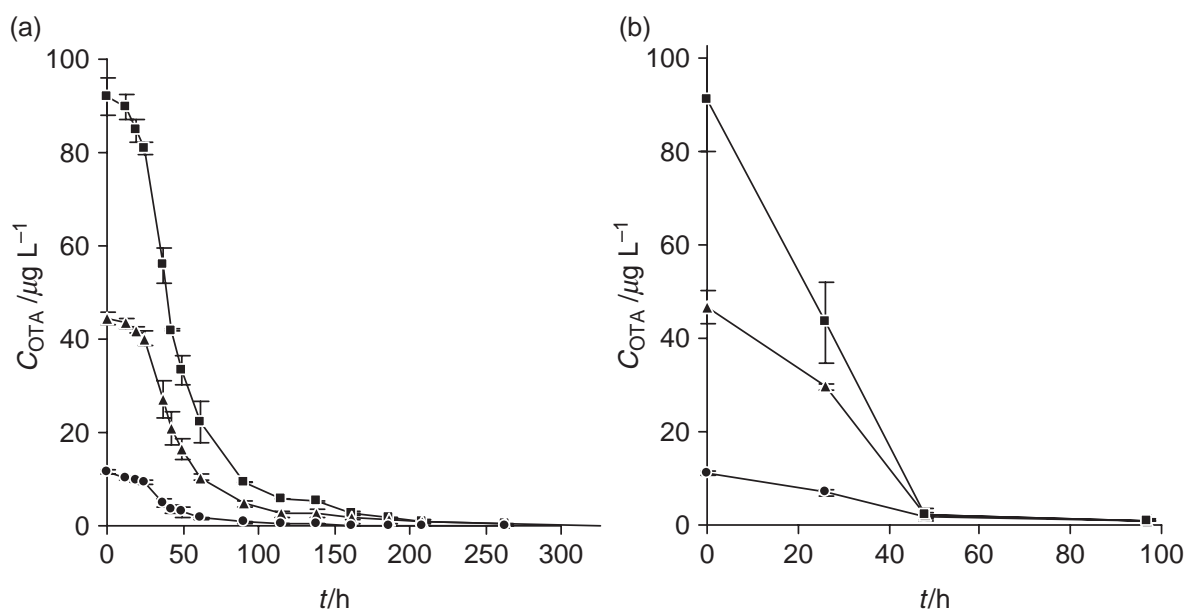

Figure 2 Ochratoxin A biodegradation in different samples: (a) synthetic substrate solution; (b) winery effluent. Error bars present standard deviations. The curves were obtained at $S_{0} / X_{0}$ ratios of $(\bullet)$

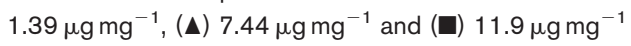



Figure 3 Specific OTA removal as a function of $S_{0} / X_{0}$, obtained with synthetic substrate solution

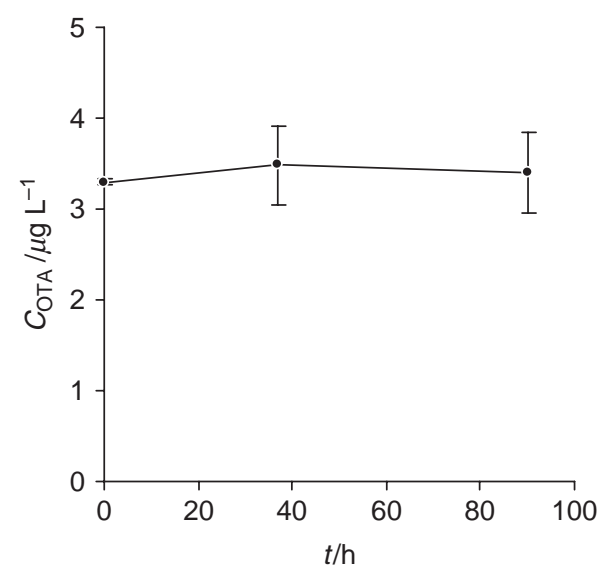




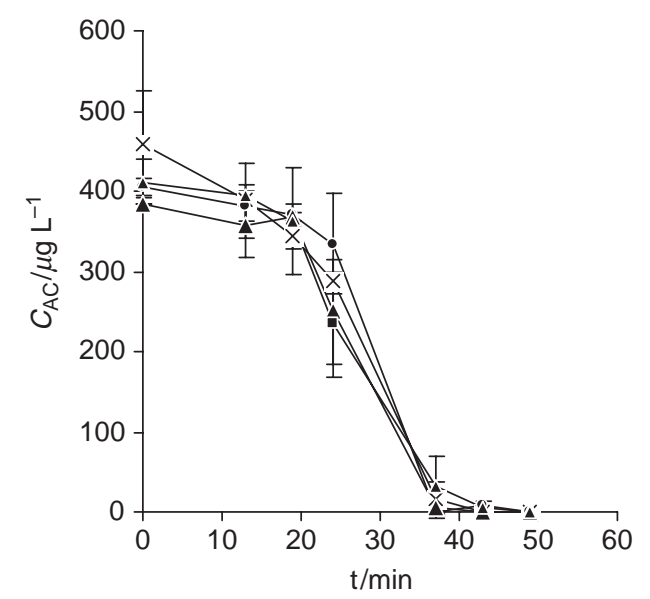

Figure 5 The effect of OTA on degradation of soluble organic matter (acetate): the essays were carried out at increasing initial OTA concentrations, respectively, $(\times) 0 \mu \mathrm{g} \mathrm{L}^{-1},(\bullet) 12 \mu \mathrm{g} \mathrm{L}^{-1},(\boldsymbol{\Lambda}) 44 \mu \mathrm{g} \mathrm{L}^{-1}$ and

(घ) $92 \mu \mathrm{g} \mathrm{L}^{-1}$. Error bars present standard deviations

As stated earlier, the evaluation of the biodegradability level of OTA with respect to OECD standards was one objective of the present study. Since a specific analysis of OTA was utilized, the OECD classification as 'readily biodegradable' calls for a 'pass-level' of $80 \%$ to be removed in the bioassay. This removal is required to occur in a specific bioassay with OTA as the sole carbon source, and within 10 days after the initial lag phase. Figure 6 represents the corresponding conditions. As illustrated, a 80\% removal occurs within less than 240 hours (10 days) for both initial concentrations, so that OTA may indeed be considered 'readily biodegradable' according to the OECD standard.

As OTA degradation occurred both with and without the presence of soluble organic matter (acetate), it was of interest to assess the influence of acetate on the respective degradation speed. A comparison of two respective degradation curves (Figure 7) illustrates that in the presence of acetate OTA removal occurs significantly faster. This effect

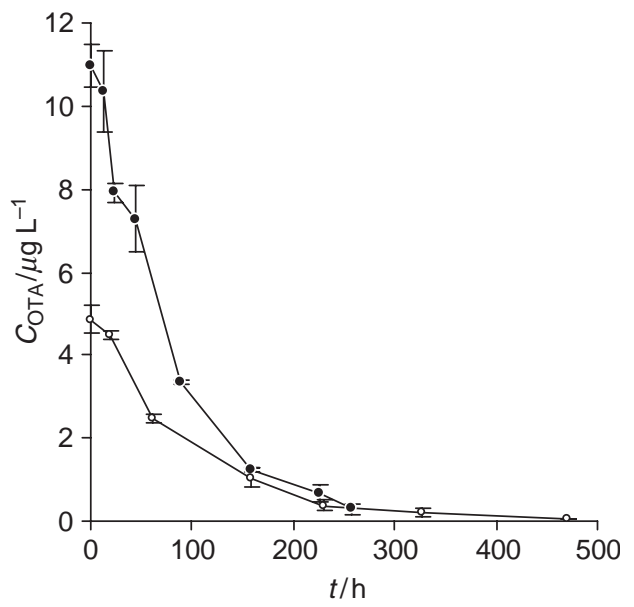

Figure 6 Ochratoxin A degradation as sole carbon source. The assays were conducted with synthetic substrate solution without acetate. Error bars present standard deviations. The curves were obtained at $S_{0} / X_{0}$ ratios of: $(O) 0.27 \mu \mathrm{g} \mathrm{mg}^{-1}$ and $(\bullet) 1.11 \mu \mathrm{g} \mathrm{mg}^{-1}$ 


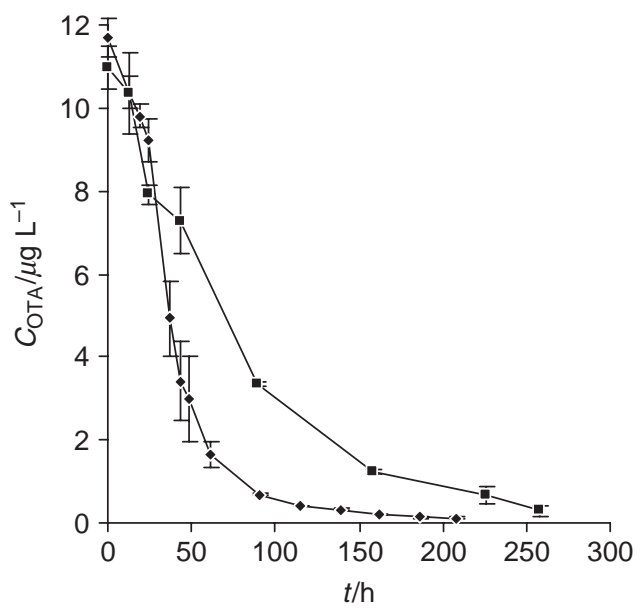

Figure 7 Illustration of acetate's effect on ochratoxin A degradation. Assays were conducted with synthetic substrate solution with acetate $(\bullet)$ and without acetate $(\square)$. Error bars present standard deviations. The curves were obtained at $S_{0} / X_{0}$ ratios of: $(\square) 1.11 \mu \mathrm{g} \mathrm{mg}^{-1}$ and $(\bullet) 1.38 \mu \mathrm{g} \mathrm{mg}^{-1}$

is probably due to the higher accumulation of biologically active biomass brought forward by the presence of acetate as a readily degradable carbon source.

The ready biodegradability of ochratoxin A, as demonstrated in this study, can be regarded as a relieving result. It would be desirable, however, in further research to detect its possible biodegradation sub-products, such as ochratoxine $\alpha$ and to determine their toxicological relevance and subsequent fate.

\section{Conclusions}

The following main conclusions can be drawn from the present study:

- OTA concentrations of up to $100 \mu \mathrm{g} \mathrm{L}^{-1}$ were degraded by activated sludge microorganisms;

- The presence of OTA in this concentration range had no significant effect on the biological removal of organic carbon;

- Microorganisms present in the activated sludge were able to degrade OTA even as single carbon source within OECD standard conditions, OTA thus may be considered as 'readily biodegradable';

- The proposed procedure could be used as a standard bioassay to assess the removal of other mycotoxins from winery effluents.

\section{Acknowledgements}

The assistance of Dr Peter Janknecht in preparing this manuscript is appreciated. The authors gratefully acknowledge the support of the Fundação para a Ciência e Tecnologia (FCT), Portugal, through the Program POCI, contract number AGR/55996/2004. Luís Abrunhosa is grateful for grant SFRH/BD/11228/2002 from FCT.

\section{References}

Abrunhosa, L., Serra, R. and Venâncio, A. (2002). Biodegradation of ochratoxin A by fungi isolated from grapes. J. Agric. Food Chem., 50(25), 7493-7496.

Blok, J. and Balk, F. (1994). Commission of the European Communities: Guidance Document for the Interpretation of Biodegradability Test Data. Technical report, BKH Consulting Engineers, Delft, The 
Brito, A.G., Peixoto, J., Oliveira, J.M., Oliveira, J.O., Costa, C., Nogueira, R. and Rodrigues, A. (2007). Brewery and winery wastewater treatment: Some focal points of design and operation. In: Utilization of By-Products and Treatment of Waste in the Food Industry, Oreopoulou, V. and Winfred, R (eds), ISEKI Series, (Vol. 3). Springer, New York.

CAST (2003). Mycotoxins: Risks in Plant, Animal and Human Systems. Ames, IA, USA: Council for Agricultural Science and Tecnology Task Force report $n^{\circ} 139$.

Chudoba, P., Capdeville, B. and Chudoba, J. (1992). Explanation of the biological meaning of the $S_{0} / X_{0}$ ratio in batch cultivation. Water Sci. Technol., 26(3-4), 743-751.

Fernandes, A., Ratola, N., Cerdeira, A., Alves, A. and Venâncio, A. (2007). Change in concentration of ochratoxin A during winemaking. Am. J. Enol. Viticult, 58, 92-96.

OECD (1984). OECD Guideline for Testing of Chemicals. 302A: Inherent Biodegradability: Modified SCAS Test. Organization For Economic Co-operation and Development, Paris.

OECD (1992). OECD Guideline for Testing of Chemicals. 301: Ready Biodegradability. Organization For Economic Co-operation and Development, Paris.

OECD (2001). OECD Guideline for Testing of Chemicals. 303: Simulation test - Aerobic Sewage Treatment. 303A: Activated Sludge Units. Organization For Economic Co-operation and Development, Paris.

Painter, H.A. (1995). Detailed Review Paper on Biodegradability Testing. Environment monograph no. 98. Environment Directorate, Organization For Economic Co-operation and Development, Paris.

Standard Methods for the Examination of Water and Wastewater (1989). 16th ed., American Public Health Association/American Water Works Association/Water Environment Federation, New York, USA.

Vishniac, W. and Santer, M. (1975). The Thiobacilli. Bacteriol Ver., 21, 195-2135. 